\title{
Holmium and titanium oxide nanolaminates by atomic layer deposition
}

Kaupo Kukli, Jun Lu, Joosep Link, Marianna Kemell, Esa Puukilainen, Mikko Heikkila, Roland Hoxha, Aile Tamm, Lars Hultman, Raivo Stern, Mikko Ritala and Markku Leskela

\section{Linköping University Post Print}

\section{Tweet}

N.B.: When citing this work, cite the original article.

Original Publication:

Kaupo Kukli, Jun Lu, Joosep Link, Marianna Kemell, Esa Puukilainen, Mikko Heikkila, Roland Hoxha, Aile Tamm, Lars Hultman, Raivo Stern, Mikko Ritala and Markku Leskela, Holmium and titanium oxide nanolaminates by atomic layer deposition, 2014, Thin Solid Films, (565), , 165-171.

http://dx.doi.org/10.1016/j.tsf.2014.06.039

Copyright: Elsevier http://www.elsevier.com/

Postprint available at: Linköping University Electronic Press http://urn.kb.se/resolve?urn=urn:nbn:se:liu:diva-110699 


\title{
Holmium and titanium oxide nanolaminates by atomic layer deposition
}

Kaupo Kukli, ${ }^{1,4}$ Jun Lu, ${ }^{2}$ Joosep Link, ${ }^{3}$ Marianna Kemell, ${ }^{1}$ Esa Puukilainen, ${ }^{1}$

Mikko Heikkilä, ${ }^{1}$ Roland Hoxha, ${ }^{4}$ Aile Tamm, ${ }^{4}$ Lars Hultman, ${ }^{2}$

Raivo Stern, ${ }^{3}$ Mikko Ritala, ${ }^{1}$ Markku Leskelä ${ }^{1}$

1) University of Helsinki, Department of Chemistry, University of Helsinki, FI-00014 Helsinki, Finland; e-mail: kaupo.kukli@helsinki.fi

2) Linköping University, Department of Physics, Chemistry and Biology (IFM), Thin Film Physics Division, SE-58183, Sweden

3) National Institute of Chemical Physics and Biophysics, EE-12618 Tallinn, Estonia

4) University of Tartu, Institute of Physics, Department of Materials Science, EE-51014 Tartu, Estonia

\begin{abstract}
Nanolaminate (nanomultilayer) thin films of $\mathrm{TiO}_{2}$ and $\mathrm{Ho}_{2} \mathrm{O}_{3}$ were grown on $\mathrm{Si}(001)$ substrates by atomic layer deposition at $300{ }^{\circ} \mathrm{C}$ from alkoxide and $\beta$-diketonate based metal precursors and ozone. Individual layer thicknesses were $2 \mathrm{~nm}$ for $\mathrm{TiO}_{2}$ and $4.5 \mathrm{~nm}$ for $\mathrm{Ho}_{2} \mathrm{O}_{3}$. As-deposited films were smooth and X-ray amorphous. After annealing at $800{ }^{\circ} \mathrm{C}$ and higher temperatures the nanolaminate structure was destroyed by solid-state reaction to form $\mathrm{Ho}_{2} \mathrm{Ti}_{2} \mathrm{O}_{7}$. The films demonstrated diamagnetic or paramagnetic behaviour in the as-deposited state. After annealing, the films possessed net magnetic moment, allowing one to record saturation magnetization and weak coercivity.
\end{abstract}

\section{Introduction}

Metal oxide multilayers in the form of superlattices or nanolaminates are of interest as functional thin films possessing advanced electronic, optical and mechanical properties. Nanolaminates may be built up artificially by sequential deposition of different oxides, e.g. $\mathrm{HfO}_{2}-\mathrm{Al}_{2} \mathrm{O}_{3}$ [1], $\mathrm{ZrO}_{2}-\mathrm{Al}_{2} \mathrm{O}_{3}$ [2-6], $\mathrm{ZrO}_{2}-\mathrm{Y}_{2} \mathrm{O}_{3}$ [7], $\mathrm{ZrO}_{2}-\mathrm{SiO}_{2}$ [7], $\mathrm{HfO}_{2}-\mathrm{Al}_{2} \mathrm{O}_{3}$ [8,9], $\mathrm{TiO}_{2}-$ 
$\mathrm{Al}_{2} \mathrm{O}_{3}$ [10-13], $\mathrm{Al}_{2} \mathrm{O}_{3}-\mathrm{Ta}_{2} \mathrm{O}_{5}$ [14-17], $\mathrm{ZrO}_{2}-\mathrm{Ta}_{2} \mathrm{O}_{5}$ [14,18], $\mathrm{HfO}_{2}-\mathrm{Ta}_{2} \mathrm{O}_{5}$ [18,19], $\mathrm{ZrO}_{2}-\mathrm{HfO}_{2}$ [18,20], $\mathrm{ZrO}_{2}-\mathrm{Er}_{2} \mathrm{O}_{3}$ [21], $\mathrm{ZrO}_{2}-\mathrm{Gd}_{2} \mathrm{O}_{3}$ [22], and $\mathrm{TiO}_{2}-\mathrm{Cr}_{2} \mathrm{O}_{3}$ [23].

Nanolaminates can assist in tailoring useful physical properties of different chemical compounds, such as band gaps, densities, refractive indexes, elasticity, homogeneity, or to exploit the formation of multiple interfaces as barriers for conduction or diffusion. Such oxide-based nanolaminates have been studied as materials able to provide good compromise between leakage current density and dielectric permittivity, enhancing charge storage capability of capacitor dielectrics while aiming at the improvement of the performance of, e.g., electroluminescent devices [10,14], field effect transistors [2,7,13,18,20], and memories $[5,9,16,21,22]$. Especially important industrially are the $\mathrm{ZrO}_{2}-\mathrm{Al}_{2} \mathrm{O}_{3}-\mathrm{ZrO}_{2}$ structures [24] used in dynamic random access memory cells. Nanolaminates may also perform as gas-diffusion barriers for reliable encapsulation of organic electronics [3], show long term durability as corrosion-protective layers [17], act as optical filters tuning the reflection from silicon substrate [11] or as hard X-ray mirrors [15]. Nanolaminates with large number of interfaces may also have reduced cross-plane thermal conductivity compared to that in chemically homogeneous films [1]. Alternate layering of different materials also reduces the overall roughness of the coating, compared to the single oxides grown to the same thickness $[1,8,24,25]$.

Nanolaminates of single oxides may be grown using different physical and chemical techniques, such as electron beam evaporation [13], sputtering [4], pulsed laser deposition [6] or, as apparently the most controlled method, atomic layer deposition (ALD) [1-3,5,7,9-12,1418,22-24,26]. Studies on ALD-grown nanolaminates containing rare earth oxides have so far been quite scarce [21,22], though, and none has been grown using Ti and Ho oxides as constituents.

This study is devoted to the description of $\mathrm{Ho}_{2} \mathrm{O}_{3}-\mathrm{TiO}_{2}$ nanolaminates, grown by atomic layer deposition. Earlier, films consisting of mixtures of $\mathrm{Ho}_{2} \mathrm{O}_{3}$ and $\mathrm{TiO}_{2}$ with variable Ho:Ti ratio have been grown by ALD [27]. The present paper will concentrate on stack of alternate $\mathrm{Ho}_{2} \mathrm{O}_{3}$ and $\mathrm{TiO}_{2}$ films with controlled interlayer thickness. Effects of heat-treatment on the film morphology, crystal structure and magnetic properties are presented and discussed. The study was initially motivated by the interest in the materials which could be deposited at low temperatures in a controlled way as structurally and optically well defined layers and, in the 
as-deposited state or after post-deposition treatment, exhibit magnetization, posssibly allowing development of multiferroic materials.

\section{Experimental details}

The films were grown in a commercial flow-type hot-wall reactor F120 (ASM Microchemistry, Ltd.) [28]. The reactor run under a pressure of about $1000 \mathrm{~Pa}$ using $\mathrm{N}_{2}$ $(99.9995 \%)$ as carrier and purging gas. $\mathrm{O}_{3}$ was used as an oxygen precursor. The $\mathrm{O}_{3}$ concentration output of the generator was $\sim 100 \mathrm{~g} / \mathrm{m}^{3}$. $\mathrm{Ho}_{2} \mathrm{O}_{3}$ layers were deposited at $300{ }^{\circ} \mathrm{C}$ using the ALD process based on $\mathrm{Ho}(\text { thd })_{3}$ (thd = 2,2,6,6-tetramethyl-3,5-heptanedionato) and $\mathrm{O}_{3}[27,29]$. $\mathrm{TiO}_{2}$ films were grown using an ALD process based on titanium tetraisopropoxide, $\mathrm{Ti}\left(\mathrm{OCH}\left(\mathrm{CH}_{3}\right)_{2}\right)_{4}$ and ozone, $\mathrm{O}_{3}$. The titanium and holmium precursors were evaporated at 35 and $125{ }^{\circ} \mathrm{C}$, respectively, from open boats inside the reactor and transported to the substrates by the carrier gas flow. The cycle times used for $\mathrm{TiO}_{2}$ were $0.5-0.5-1.0-0.5 \mathrm{~s}$, and those for $\mathrm{Ho}_{2} \mathrm{O}_{3}$ were 1.0-1.5-2.0-2.0 s, denoting the sequence metal precursor pulse purge $-\mathrm{O}_{3}$ pulse - purge. $\mathrm{TiO}_{2}-\mathrm{Ho}_{2} \mathrm{O}_{3}$ nanolaminates were grown using the total sequence of $10 \times\left[100 \times \mathrm{TiO}_{2}+250 \times \mathrm{Ho}_{2} \mathrm{O}_{3}\right]+100 \times \mathrm{TiO}_{2}$ cycles. The substrates were pieces of undoped $\mathrm{Si}(100)$ covered with $1.5-2.0 \mathrm{~nm}$ thick native $\mathrm{SiO}_{2}$. Selected samples were annealed at 600, 800 or $1000{ }^{\circ} \mathrm{C}$ under a $\mathrm{N}_{2}$ flow for $30 \mathrm{~min}$.

High-resolution transmission electron microscopy (HRTEM) studies for characterization of the cross-sections of the nanolaminate structure were carried out using a FEI Tecnai G2 TF20 UT instrument with a field emission gun operated at $200 \mathrm{kV}$ with a point resolution of 0.19 $\mathrm{nm}$. The surface morphology images were taken and the film thicknesses measured by a Hitachi S-4800 scanning electron microscope equipped with an Oxford INCA 350 energy dispersive X-ray (EDX) spectrometer. The EDX spectra were measured at $20 \mathrm{keV}$. The beam current and spectrometer gain were determined from a calibration measurement performed under the same beam conditions. The film thicknesses and ratios of the different metals were calculated from the $\mathrm{k}$ ratios of $\mathrm{Ho} \mathrm{K} \alpha$ and $\mathrm{Ti} \mathrm{K} \alpha \mathrm{X}$-ray lines measured with the calibrated beam. The calculations were done with a GMRFILM program [30] assuming a density of 5 $\mathrm{g} / \mathrm{cm}^{3}$ for $\mathrm{TiO}_{2}$ slightly doped and thus densified by holmium. 
A Sopra GES-5E variable angle spectroscopic ellipsometer was used to determine the thickness (d) and optical properties (n, k) using 'Winelli II' software. Layer thickness and optical constants (n, k) were determined from the ellipsometric tan $\psi$ and $\cos \Delta$ parameters [40]. All the main parameters, $\mathrm{d}, \mathrm{n}$, and k parameters were obtained for each layer using a LevenbergMarquardt non-linear regression algorithm. Measurements of were generally made at incidence and reflectance angle of $75^{\circ}$. Layers of $\mathrm{Ho}_{2} \mathrm{O}_{3}$ and $\mathrm{TiO}_{2}$ were modelled as homogeneous mixtures of supposedly dense materials and addition of void content for refractive index, $\mathrm{n}$, and absorption coefficient, $\mathrm{k}$, adjustment. The optical properties of thin films were examined in air at ambient conditions. Optical constants quoted in this paper will further refer to those measured at $633 \mathrm{~nm}$ wavelength. In addition, using the same optical model, thicknesses were measured as a matrix laid over an area of $25 \mathrm{~cm}^{2}$ with steps of $7 \mathrm{~mm}$ in $\mathrm{X}$ and Y horizontal directions in order to profile the thickness along and across the gas flow direction in the ALD reactor.

The thicknesses of the films were measured and their crystal structure evaluated by X-ray reflectometry (XRR) and by grazing incidence X-ray diffraction (GIXRD), respectively, using a PANalytical X'Pert PRO X-ray diffractometer with $\mathrm{Cu} \mathrm{K}_{\alpha}$ source. For the GIXRD, the incidence angle was set at $1 \mathrm{deg}$. For atomic force microscopy (AFM) studies a MultiMode V equipped with a NanoScope V controller (Veeco Instruments) was used. Tapping mode height and phase images were measured in air using phosphorus-doped silicon probe (RTESP) delivered by Veeco Instruments. Phase imaging detects e.g. variations in composition and it can be applied in order to map different components, such as amorphous and crystalline regions present in the material. Image processing and data analysis were performed with a NanoScope software version 7.30. The scan area was $2 \mu \mathrm{m} \times 2 \mu \mathrm{m}$ and the Z-scale $25 \mathrm{~nm}$ in all the AFM images.

A selection of films was subjected to magnetic measurements. The measurements were performed using the Vibrating Sample Magnetometer option of the Physical Property Measurement System (PPMS) 14T (Quantum Design). Rectangular samples with dimensions of ca. $7 \mathrm{~mm} \times 4 \mathrm{~mm}$ were fixed with GE vanish on commercial quartz sample holders (Quantum Design). The samples were cooled in a magnetic field of $477.6 \mathrm{kA} / \mathrm{m}$ parallel to the film surface and the temperature dependence of magnetization was measured in the temperature range from 10 to $310 \mathrm{~K}$ in the presence of the same field. The hysteresis measurements were performed by scanning the magnetic fields from $-477.6 \mathrm{kA} / \mathrm{m}$ to +477.6 
$\mathrm{kA} / \mathrm{m}$ at temperatures selected in the range of 10-300 K. Diamagnetic signal arising from the silicon substrate was subtracted from the general magnetization curve for certain samples in which the ferromagnetic-like response was detected.

\section{Results and discussion}

\subsection{Film growth and formation}

XRR measurements of thicker binary oxide reference films showed that the growth rate of $\mathrm{Ho}_{2} \mathrm{O}_{3}$ layers on $\mathrm{SiO}_{2} / \mathrm{Si}$ substrates in these experiments was $0.025 \mathrm{~nm} /$ cycle. The growth rate of $\mathrm{TiO}_{2}$ thin films was significantly higher, reaching $0.045 \mathrm{~nm} /$ cycle. These growth rates do not exactly correspond to the growth rate during the first few nanometers because the thicknesses of both $\mathrm{Ho}_{2} \mathrm{O}_{3}$ and $\mathrm{TiO}_{2}$ single layers in the nanolaminate remained below the values expected on the basis of growth rates of reference films. The difference was more prominent in the case of $\mathrm{TiO}_{2}$ than with $\mathrm{Ho}_{2} \mathrm{O}_{3}$. Figure 1 shows a cross-sectional TEM image taken from the nanolaminate in the as-deposited state. One can clearly see the periodical stack consisting of distinct $\mathrm{Ho}_{2} \mathrm{O}_{3}$ and $\mathrm{TiO}_{2}$ layers. The thickness of the constituent layers in the laminate grown using the recipe $10 \times\left[100 \times \mathrm{TiO}_{2}+250 \times \mathrm{Ho}_{2} \mathrm{O}_{3}\right]+100 \times \mathrm{TiO}_{2}$ cycles remained below $5 \mathrm{~nm}$. EDX composition profile (Fig. 2) from the nanolaminate further confirms that the film consists of chemically different alternating layers. Figures $\mathbf{1}$ and $\mathbf{2}$ also show that the layer interfaces remain relatively flat up to the top surface with a slightly accumulated roughness limited to less that one individual layer thickness (in the order of 1 $\mathrm{nm})$.

Refractive indices measured from the reference single metal oxide films were $2.39 \pm 0.02$ and $1.98 \pm 0.01 \mathrm{~nm}$, for $\mathrm{TiO}_{2}$ and $\mathrm{Ho}_{2} \mathrm{O}_{3}$, respectively, at the wavelength of $633 \mathrm{~nm}$. Growth rates for single layer films, deposited at temperature of $300{ }^{\circ} \mathrm{C}$, were calculated to be $0.045 \mathrm{~nm} / \mathrm{cycle}$ and $0.027 \mathrm{~nm} /$ cycle for $\mathrm{TiO}_{2}$ and $\mathrm{Ho}_{2} \mathrm{O}_{3}$, matching the values obtained by XRR. Repeated units of the $\mathrm{Ho}_{2} \mathrm{O}_{3} / \mathrm{TiO}_{2}$ bilayer were assumed in constructing a 21 layers optical model for the $\mathrm{Ho}_{2} \mathrm{O}_{3}-\mathrm{TiO}_{2}$ nanolaminate, with an additional capping layer of $\mathrm{TiO}_{2}$. The multilayer stack was modelled by fixing refractive index $n$ and absorption coefficient $\mathrm{k}$ for each layer to that of the corresponding single-layer reference film allowing variation of the thickness throughout the layers by $\sim 1 \mathrm{~nm}$ in accord with the TEM results (Fig. 1). Further, by adding void content into each layer, fitting of both thickness and refractive index was accomplished using the standard 
three-angle data sets. Fitting of the three-angle data sets and results as thickness (d) and refractive index values (n) for each layer are summarized in Fig. 3.

The values of thicknesses for each layer of $\mathrm{TiO}_{2}$ and $\mathrm{Ho}_{2} \mathrm{O}_{3}$ were preliminarily based on calculations taking into account the number of cycles. This kind of approach has also been applied earlier for the $\mathrm{TiO}_{2}$ and $\mathrm{Al}_{2} \mathrm{O}_{3}$ layers forming respective nanolaminate structure [12]. Refractive index in $\mathrm{TiO}_{2}$ layers was basically varying around the corresponding single layer value $(2.39$ at $633 \mathrm{~nm})$. The refractive index values in both $\mathrm{TiO}_{2}$ and $\mathrm{Ho}_{2} \mathrm{O}_{3}$ layers were quite stable throughout the multilayer stack indicating the stability of the growth and uniformity of the constituent layers [12,41]. Moderate variations in the layer thicknesses could be caused by errors in the fitting procedure.

Thickness distribution over an area of $5 \times 5=25 \mathrm{~cm}^{2}$ was measured as also shown in Figure 3 (the bottom panel). Obviously, the films grown were quite uniform with thickness deviation not significantly exceeding $10 \%$ of the mean value. The nanolaminate were somewhat thicker close to the leading edge of the substrate and the thickness decreased steadily towards the trailing edge. This kind of thickness profile is common to ALD films grown in our type pf flow-type reactors, as observed also in a study on the growth of $\mathrm{TiO}_{2}$ from TTIP and $\mathrm{H}_{2} \mathrm{O}$ [42] . The longitudinal thickness profiles may develop due to incomplete purging of precursors, secondary surface reactions or partial blocking of the surface adsorption sites from the precursors by the reaction byproducts [43].

\subsection{Film structure and morphology}

The reference $25-45 \mathrm{~nm}$ thick $\mathrm{Ho}_{2} \mathrm{O}_{3}$ and $\mathrm{TiO}_{2}$ films were crystallized already in the asdeposited state. $\mathrm{Ho}_{2} \mathrm{O}_{3}$ films were crystallized to the cubic phase as observed earlier using similar precursor chemistry [29] whereas $\mathrm{TiO}_{2}$ possessed anatase structure, also similarly to that observed before, though using $\mathrm{H}_{2} \mathrm{O}$, then, as the oxygen precursor [42]. A recent study devoted to the mixing of $\mathrm{Ho}_{2} \mathrm{O}_{3}$ and $\mathrm{TiO}_{2}$ and doping $\mathrm{TiO}_{2}$ with $\mathrm{Ho}_{2} \mathrm{O}_{3}$ revealed that the crystallization temperature was significantly raised together with the Ho:Ti cation ratio approaching 1:1, i.e. that in $\mathrm{Ho}_{2} \mathrm{Ti}_{2} \mathrm{O}_{7}$ [27].

The average Ho:Ti cation ratio measured by EDX in the $\mathrm{TiO}_{2}-\mathrm{Ho}_{2} \mathrm{O}_{3}$ nanolaminate was 1.1. The composition of these films thus became close to that of stoichiometric holmium titanate. 
Similarly to the $\mathrm{TiO}_{2}-\mathrm{Ho}_{2} \mathrm{O}_{3}$ mixture films, the nanolaminates remained $\mathrm{X}$-ray amorphous in the as-deposited state, neither were they crystallized after annealing at $800{ }^{\circ} \mathrm{C}$ (Fig. 4). In accord with HRTEM observations (Fig. 1), some crystallization could be detected in $\mathrm{Ho}_{2} \mathrm{O}_{3}$ interlayers already in the as-deposited state, whereas the $\mathrm{TiO}_{2}$ layers remained completely disordered. The crystallization in $\mathrm{Ho}_{2} \mathrm{O}_{3}$ layers was evidently not extensive enough to be recognized by X-ray diffraction. Upon annealing at $1000{ }^{\circ} \mathrm{C}$, the films crystallized into $\mathrm{Ho}_{2} \mathrm{Ti}_{2} \mathrm{O}_{7}$, as determined by XRD (Fig. 4). Signatures of $\mathrm{Ho}_{2} \mathrm{O}_{3}$ and/or $\mathrm{TiO}_{2}$ were not detected in the patterns, neither were perovskite $\mathrm{HoTiO}_{3}$ reflections [44] observed. The patterns were quite similar, regarding the most intense peaks, to those obtained earlier, e.g., for $\mathrm{Ho}_{2} \mathrm{Ti}_{2} \mathrm{O}_{7}$ synthesized via solid state reaction of the component oxides. [45] One can suppose that the ternary pyrochlore structure is energetically the most favored and the easiest one to form, whereas the rest of the material remains amorphous or too weakly crystallized for X-ray diffraction.

In the sample annealed after deposition at temperatures ranging from 800 to $1000{ }^{\circ} \mathrm{C}$ the nanolaminate structure was destroyed. The originally distinct $\mathrm{TiO}_{2}$ and $\mathrm{Ho}_{2} \mathrm{O}_{3}$ layers were mixed and the elemental composition map became homogeneous throughout the film thickness (Fig. 5). One can see in the TEM images that the distinctive multilayer structure disappeared and, at the same time, round hollow-like features appeared, embedded in the host oxide film. The appearance of hollow regions might be attributed to the Kirkendall effect, i.e. the motion of the boundary layer between two metals or metal oxides due to the difference in diffusion rates of the cations. The Kirkendall effect can arise when two distinct materials are placed in contact to each other and their interdiffusion occurs by a vacancy mechanism. The Kirkendall effect can become observable by the formation of hollow regions, pores or voids during the diffusion process. These voids may accumulate vacancies and expand further in order to restore equilibrium in the material. Kirkendall effect is mostly observed in metal alloys, rather than in other materials such as mixtures of metal oxides. Nevertheless, there is,a study by Yang et al. [46], devoted to $\mathrm{ALD}$ of $\mathrm{Al}_{2} \mathrm{O}_{3}$ thin films on $\mathrm{ZnO}$ nanorods. After annealing the $\mathrm{ZnO} / \mathrm{Al}_{2} \mathrm{O}_{3}$ core-shell layers were mixed and hollow $\mathrm{ZnAl}_{2} \mathrm{O}_{4}$ tube-like structures formed via Kirkendall process. It is thus reasonable that ternary metal oxides, such as $\mathrm{Ho}_{2} \mathrm{Ti}_{2} \mathrm{O}_{7}$, form as a result of interdiffusion between the initially distinct regions of constituent binary oxides, i.e. $\mathrm{Ho}_{2} \mathrm{O}_{3}$ and $\mathrm{TiO}_{2}$. 
The nanolaminate in the as-deposited state possessed a smooth surface as revealed by AFM (Fig. 6). The surface is clean and homogeneous, i.e. morphologically featureless. The average particle diameter can be estimated to be in the range of $20-30 \mathrm{~nm}$. The rms roughness remains as low as $0.50 \mathrm{~nm}$. As mentioned above, such films required annealing at least at $800{ }^{\circ} \mathrm{C}$ in $\mathrm{N}_{2}$ for $30 \mathrm{~min}$ for the initiation of crystallization and were clearly transformed into the ternary crystalline phase upon annealing at $1000{ }^{\circ} \mathrm{C}$. Naturally, the films also roughened upon annealing. Already upon annealing at $800{ }^{\circ} \mathrm{C}$, features resembling particles, crystals or even blisters were observed on the film surface (Fig. 6). These round shaped features may correspond to the voids visible in TEM. The surface features are different in size and shape, with the maximum height of $\sim 30 \mathrm{~nm}$, visible in both height and phase images. The density of these features varied from place to place on the surface causing also the rms roughness to vary between 0.7 and $1.6 \mathrm{~nm}$.

The nanolaminate was also investigated by means of high-temperature X-ray reflectivity (HTXRR) (Fig. 7). Based on the superlattice peak intensity, the laminate structure remains intact up to $425^{\circ} \mathrm{C}$. At higher temperatures up to $725{ }^{\circ} \mathrm{C}$ the intensity of that peak decreases indicating layer mixing. When heating further, the intensity drops markedly and the fringes become less defined because of increased roughness most likely caused by the crystallization of the film. This temperature range is well supported by crystallization observed in GIXRD measurements.

\subsection{Magnetic behavior}

Fig. 8 demonstrates magnetization in the as-deposited $\mathrm{Ho}_{2} \mathrm{O}_{3}-\mathrm{TiO}_{2}$ nanolaminate on a $\mathrm{Si}$ substrate as functions of the measurement temperature and external magnetic field. One can see that the net magnetic moment could be measured in the sample at low temperatures, but it decreased to zero already at about $100 \mathrm{~K}$. In the $\boldsymbol{M}-\boldsymbol{H}$ measurements, the nanolaminate did not show ferromagnetic behavior, but exhibited paramagnetic behavior at low temperatures, i.e. at $10 \mathrm{~K}$. At room temperature the diamagnetic response from the sample was dominating. This is not surprising, considering that $\mathrm{Ho}_{2} \mathrm{O}_{3}$ and $\mathrm{TiO}_{2}$ are paramagnetic and diamagnetic, respectivly, and no additional phases like $\mathrm{Ho}_{2} \mathrm{Ti}_{2} \mathrm{O}_{7}$ or $\mathrm{HoTiO}_{3}$ were found in the as-deposited nanolaminates. In the sample annealed at $800{ }^{\circ} \mathrm{C}$, i.e. after conversion of the multilayer to a more homogeneous structure, appearance of voids, and formation of ternary $\mathrm{Ho}_{2} \mathrm{Ti}_{2} \mathrm{O}_{7}$ phase, 
the magnetization tended to saturate apparent in the whole temperature range examined. In accord with the measured magnetization-vs-temperature curve (Fig. 9), the magnetization was measurable in the whole temperature range examined, and remained clearly above the zero around the room temperature as well. Certain transition was observed at $200 \mathrm{~K}$. The transition occurred analogously to that observed earlier in double perovskites, such as epitaxial $\mathrm{Bi}_{2} \mathrm{CoMnO}_{6}$ synthesized by a solid state chemical route [47], $\mathrm{La}_{2} \mathrm{CoMnO}_{6}$ [48], or in laser ablated epitaxial $\mathrm{La}_{2} \mathrm{NiMnO}_{6}$ films [49]. The first magnetic transition at $180-200 \mathrm{~K}$ is incomplete as the drop in magnetization is rather weak. In the $\boldsymbol{M}-\boldsymbol{H}$ curves, after substracting linear para- and diamagnetic components, saturation magnetization below $4.2 \times 10^{-8} \mathrm{~A} \times \mathrm{cm}^{2}$ could be estimated at $300 \mathrm{~K}$. The magnetization was very soft, with the coercive force not exceeding $4000 \mathrm{~A} / \mathrm{m}$. Saturative magnetization probably belongs to the already crystallized $\mathrm{Ho}_{2} \mathrm{Ti}_{2} \mathrm{O}_{7}$, while paramagnetic contibution is due to the remaining amorphous phases. These in-plane magnetization loops were also similar to those observed earlier in double perovskites [47] and holmium titanates [45] in terms of their soft behavior.

\section{Conclusions}

$\mathrm{Ho}_{2} \mathrm{O}_{3}-\mathrm{TiO}_{2}$ nanolaminates were grown by atomic layer deposition. Smooth films consisting of distinct metal oxide layers were formed, as recognized by microscopy and ellipsometric measurements. Post-deposition heat-treatment above $800{ }^{\circ} \mathrm{C}$ destroyed the multilayer structure and led to the formation of a crystalline ternary phase, $\mathrm{Ho}_{2} \mathrm{Ti}_{2} \mathrm{O}_{7}$. The films with initiated crystallization exhibited magnetic performance with saturative magnetization up to 5 $\times 10^{-8}{\mathrm{~A} \times \mathrm{cm}^{2}}^{2}$ and hysteresis within $3980 \mathrm{~A} / \mathrm{m}$ in magnetization-versus-external magnetic field curves.

\section{Acknowledgements}

The work was supported by Finnish Centre of Excellence in Atomic Layer Deposition (Academy of Finland), Knut and Alice Wallenberg Foundation (Sweden), and research projects IUT-24 and PUT170 (Estonian Research Agency). 


\section{References}

[1] N. T. Gabriel, J. J. Talghader, Thermal conductivity and refractive index of hafniaalumina nanolaminates, J. Appl. Phys. 110 (2011) pp. 043526.

[2] W.F.A. Besling, E. Young, T. Conard, C. Zhao, R. Carter, W. Vandervorst, M. Caymax, S. De Gendt, M. Heyns, J. Maes, M. Tuominen, S. Haukka, Characterisation of ALCVD $\mathrm{Al}_{2} \mathrm{O}_{3}-\mathrm{ZrO}_{2}$ nanolaminates, link between electrical and structural properties, J. Non-Cryst. Solids 303 (2002) 123-133.

[3] J. Meyer, P. Görrn, F. Bertram, S. Hamwi, T. Winkler, H.-H. Johannes, T. Weimann, P. Hinze, T. Riedl, W. Kowalsky, $\mathrm{Al}_{2} \mathrm{O}_{3} / \mathrm{ZrO}_{2}$ nanolaminates as ultrahigh gas-diffusion barriers - A strategy for reliable encapsulation of organic electronics, Adv. Mater. 2009, 21, 18451849.

[4] C.R. Aita, Tailored ceramic film growth at low temperature by reactive sputter deposition, Critical Rev. Solid State Mater. Sci. 23 (1998) 205-274.

[5] Z. Tang, X. Zhu, H. Xu, Y. Xia, J. Yin, Z. Liu, A. Li, F. Yan, Impact of the interfaces in the charge trap layer on the storage characteristics of $\mathrm{ZrO}_{2} / \mathrm{Al}_{2} \mathrm{O}_{3}$ nanolaminate-based charge trap flash memory cells, Mater. Lett. 92 (2013) 21-24.

[6] G. Balakrishnan, T.N. Sairam, V.R. Reddy, P. Kuppusami, J.I. Song, Microstructure and optical properties of $\mathrm{Al}_{2} \mathrm{O}_{3} / \mathrm{ZrO}_{2}$ nanomultilayer thin films prepared by pulsed laser deposition, Mater. Chem. Phys. 140 (2013) 60-65.

[7] L. Zhong, F. Chen, S. A. Campbell, W. L. Gladfelter, Nanolaminates of zirconia and silica using atomic layer deposition, Chem. Mater. 16 (2004) 1098-1103.

[8] M. de Pauli, A. Malachias, H. Westfahl, Jr., J. Bettini, A. Ramirez, G. S. Huang, Y. F. Mei, O. G. Schmidt, Study of roughness evolution and layer stacking faults in short-period atomic layer deposited $\mathrm{HfO}_{2} / \mathrm{Al}_{2} \mathrm{O}_{3}$ multilayers, J. Appl. Phys. 109 (2011) pp. 063524.

[9] O. Sneh, R. B. Clark-Phelps, A. R. Londergan, J. Winkler, T. E. Seidel, Thin film atomic layer deposition equipment for semiconductor processing, Thin Solid Films 402 (2002) 248261. 
[10] Y. S. Kim, S. J. Yun, Nanolaminated $\mathrm{Al}_{2} \mathrm{O}_{3}-\mathrm{TiO}_{2}$ thin films grown by atomic layer deposition, J. Cryst. Growth 274 (2005) 585-593.

[11] S. Zaitsu, T. Jitsuno, M. Nakatsuka, T. Yamanaka, S. Motokoshi, Optical thin ®lms consisting of nanoscale laminated layers , Appl. Phys. Lett. Vol. 80 (2002) 2442-2444.

[12] D. R. G. Mitchell, D. J. Attard, K. S. Finnie, G. Triani, C.J. Barbé, C. Depagne, J.R. Bartlett, TEM and ellipsometry studies of nanolaminate oxide films prepared using atomic layer deposition, Appl. Surf. Sci. 243 (2005) 265-277.

[13] V. Mikhelashvili, G. Eisenstein, Composition, surface morphology and electrical characteristics of $\mathrm{Al}_{2} \mathrm{O}_{3}-\mathrm{TiO}_{2}$ nanolaminates and $\mathrm{AlTiO}$ films on silicon, Thin Solid Films 515 (2006) 346-352.

[14] K. Kukli, J. Ihanus, M. Ritala, M. Leskelä, Properties of Ta2O5-based dielectric nanolaminates deposited by atomic layer epitaxy, J. Electrochem. Soc. 144 (1997) 300-306.

[15] A. Szeghalmi, S. Senz, M. Bretschneider, U. Gösele, M. Knez, All dielectric hard x-ray mirror by atomic layer deposition, Appl. Phys. Lett. 94 (2009) 133111-3.

[16] S.W. Smith, K.G. McAuliffe, J.F. Conley Jr., Atomic layer deposited high-k nanolaminate capacitors, Solid-State Electronics 54 (2010) 1076-1082.

[17] E. Härkönen, B. Diaz, b J. Światowska, V. Maurice, A. Seyeux, M. Vehkamäki, T. Sajavaara, M. Fenker, P. Marcus, M. Ritala, Corrosion protection of steel with oxide nanolaminates grown by atomic layer deposition, J. Electrochem. Soc. 158 (2011) C369C378.

[18] H. Zhang, R. Solanki, Atomic layer deposition of high dielectric constant nanolaminates, J. Electrochem. Soc., 148 (2001) F63-F66.

[19] K. Kukli, J. Ihanus, M. Ritala, M. Leskelä, Tailoring the dielectric properties of $\mathrm{HfO}_{2^{-}}$ $\mathrm{Ta}_{2} \mathrm{O}_{5}$ nanolaminates, Appl. Phys. Lett. 68 (1996) 3737-3739.

[20] H. Kim, P. C. McIntyre, K. C. Saraswat, Microstructural evolution of $\mathrm{ZrO}_{2}-\mathrm{HfO}_{2}$ nanolaminate structures grown by atomic layer deposition, J. Mater. Res. 19 (2004) 643-650. 
[21] A. Tamm, M. Heikkilä, M. Kemell, J. Kozlova, K. Kukli, V. Sammelselg, M. Ritala, M. Leskelä, Atomic layer deposition and characterization of zirconium oxide-erbium oxide nanolaminates, Thin Solid Films 519 (2010) 666-673.

[22] I. Jõgi, A. Tamm, K. Kukli, M. Kemell, J. Lu, T. Sajavaara, M. Ritala, M. Leskelä, J. Electrochem. Soc., Investigation of $\mathrm{ZrO}_{2}-\mathrm{Gd}_{2} \mathrm{O}_{3}$ based high-k materials as capacitor dielectrics, 157 (2010) G202-G210.

[23] V. Sammelselg, A. Tarre, J. Lu, J. Aarik, A. Niilisk, T. Uustare, I. Netšipailo, R. Rammula, R. Pärna, A. Rosental, Structural characterization of $\mathrm{TiO}_{2}-\mathrm{Cr}_{2} \mathrm{O}_{3}$ nanolaminates grown by atomic layer deposition, Surf. Coat. Tech. 204 (2010) 2015-2018.

[24] H. J. Cho, Y. D. Kim, D. S. Park, E. Lee, C. H. Park, J. S. Jang, K. B. Lee, H. W. Kim, Young Jong Ki, Il Keun Han, Yong Wook Song, New TIT Capacitor with $\mathrm{ZrO}_{2} / \mathrm{Al}_{2} \mathrm{O}_{3} / \mathrm{ZrO}_{2}$ dielectrics for 60nm and below DRAMs, Solid-State Electronics 51 (2007) 1529-1533.

[25] M. Ritala, M. Leskelä, L. Niinistö, T. Prohaska, G. Friedbacher, M. Grasserbauer, Surface roughness reduction in atomic layer epitaxy growth of titanium dioxide thin films, Thin Solid Films 249 (1994) 155-162.

[26] M. Laitinen, T. Sajavaara, M. Rossi, J. Julin, R. L. Puurunen, T. Suni, T. Ishida, H. Fujita, K. Arstila, B. Brijs, H. J. Whitlow, Depth profiling of $\mathrm{Al}_{2} \mathrm{O}_{3}+\mathrm{TiO}_{2}$ nanolaminates by means of a time-of-flight energy spectrometer, Nucl. Instr. Methods Phys. Res. B 269 (2011) 3021-3024.

[27] K. Kukli, M. Kemell, M. C. Dimri, E. Puukilainen, A. Tamm, R. Stern, M. Ritala, M. Leskelä, Holmium titanium oxide thin films grown by atomic layer deposition, to be published.

[28] T. Suntola, Atomic layer epitaxy, Thin Solid Films 216 (1992) 84-89.

[29] J. Päiväsaari, M. Putkonen, L. Niinistö, A comparative study on lanthanide oxide thin films grown by atomic layer deposition, Thin Solid Films 472 (2005) 275-281.

[30] R. A. Waldo, Microbeam Analysis, San Francisco Press, San Francisco, CA,1988.

[40] H. Fujiwara, Spectroscopic Ellipsometry Principles and Applications, John Wiley \& Sons Ltd, 2007. 
[41] P. Eiamchai, P. Chindaudom, A. Pokaipisit, P. Limsuwan, A spectroscopic ellipsometry study of $\mathrm{TiO}_{2}$ thin films prepared by ion-assisted electron-beam evaporation, Curr. Appl. Phys. 9 (2009) 707-712.

[42] M. Ritala, M. Leskelä, L. Niinistö, P. Haussalo, Titanium isopropoxide as a precursor in atomic layer epitaxy of titanium dioxide thin films, Chem. Mater. 5 (1993) 1174-1181.

[43] H. Siimon, J.Aarik, Thickness profiles of thin films caused by secondary reactions in flow-type atomic layer deposition reactors, J. Phys. D: Appl. Phys. 30 (1997) 1725-1728.

[44] T.-M. Pan, M.-D. Huang, C.-W. Lin, M.-H. Wu, Development of high-k $\mathrm{HoTiO}_{3}$ sensing membrane for pH detection and glucose biosensing, Sens. Actuators B 144 (2010) 139-145.

[45] X. W. Dong, K. F. Wang, S. J. Luo, J. G. Wan, J.-M. Liu, Coexistence of magnetic and ferroelectric behaviors of pyrochlore $\mathrm{Ho}_{2} \mathrm{Ti}_{2} \mathrm{O}_{7}$, J. Appl. Phys. 106 (2009) 104101. [46] Y. Yang, D. S. Kim, R. Scholz, M. Knez, S. M. Lee, U. Gösele, M. Zacharias, Hierarchical three-dimensional $\mathrm{ZnO}$ and their shape-preserving transformation into hollow $\mathrm{ZnAl}_{2} \mathrm{O}_{4}$ nanostructures, Chem. Mater. 20 (2008) 3487-3494.

[47] M. P. Singh, K. D. Truong, P. Fournier, P. Rauwel, E. Rauwel, L. P. Carignan, D. Ménard, Anomalously large ferromagnetic Curie temperature of epitaxial $\mathrm{Bi}_{2} \mathrm{CoMnO}_{6}$ thin films, Appl. Phys. Lett. 92 (2008) 112505.

[48] R. I. Dass, J. B. Goodenough, Multiple magnetic phases of $\mathrm{La}_{2} \mathrm{CoMnO}_{6-\delta}(0 \leq \delta \leq 0.05)$ Phys. Rev. B 67 (2003) 014401.

[49] M. P. Singh, C. Grygiel, W. C. Sheets, Ph. Boullay, M. Hervieu, W. Prellier, B. Mercey, Ch. Simon, B. Raveau, Absence of long-range Ni/Mn ordering in ferromagnetic $\mathrm{La}_{2} \mathrm{NiMnO}_{6}$ thin films, Appl. Phys. Lett. 91 (2007) 012503. 


\section{CAPTIONS TO FIGURES:}

Fig. 1

Cross-sectional TEM (upper panel) and HRTEM (lower panel) images of a $\mathrm{Ho}_{2} \mathrm{O}_{3}-\mathrm{TiO}_{2}$ nanolaminate in the as-deposited state. The constituent layer materials are indicated by labels.

Fig. 2

Cross-sectional EDX composition profiling of the $\mathrm{Ho}_{2} \mathrm{O}_{3}-\mathrm{TiO}_{2}$ nanolaminate in the asdeposited state. The elements detected are indicated by labels. Due to the higher $\mathrm{O}$ concentration in $\mathrm{TiO}_{2}$ compared to that in $\mathrm{Ho}_{2} \mathrm{O}_{3}$, the $\mathrm{O}$ profile is following the Ti profile rather than Ho (color online).

Fig. 3

Spectroscopic ellipsometry results of the $\mathrm{Ho}_{2} \mathrm{O}_{3}-\mathrm{TiO}_{2}$ nanolaminate in the as-deposited state. Upper panels depict the $\Delta$ and $\psi$ curves measured together with the fitting results. The $3^{\text {rd }}$ panel from the top represents the multilayer schematics with the thicknesses and refractive indexes giving the best fit with measured spectra. The bottom panel demonstrates total multilayer thickness map over a $\operatorname{Si}(100)$ substrate with an area of $5 \times 5 \mathrm{~cm} \times \mathrm{cm}$.

Fig. 4

X-ray diffraction patterns from the $\mathrm{Ho}_{2} \mathrm{O}_{3}-\mathrm{TiO}_{2}$ nanolaminate in the as-deposited state, and after annealing at 800 and $1000{ }^{\circ} \mathrm{C}$ in $\mathrm{N}_{2}$ for 30 min. Miller indexes assigned after crystallization to the pyrochlore phase $\mathrm{Ho}_{2} \mathrm{Ti}_{2} \mathrm{O}_{7}$ are indicated.

Fig. 5

HRTEM images in two different scales (top and middle panels) and compositional EDX map (bottom panel) from the $\mathrm{Ho}_{2} \mathrm{O}_{3}-\mathrm{TiO}_{2}$ nanolaminate annealed at $1000{ }^{\circ} \mathrm{C}$ in $\mathrm{N}_{2}$ for $30 \mathrm{~min}$. (color online)

Fig. 6

Atomic force microscopy height (left column) and phase (right column) images of the $\mathrm{Ho}_{2} \mathrm{O}_{3}-\mathrm{TiO}_{2}$ nanolaminate in the as-deposited state (upper row) and after annealing at $800{ }^{\circ} \mathrm{C}$ in $\mathrm{N}_{2}$ for 30 min (lower row). 


\section{Fig. 7}

X-ray reflectivity patterns from $\mathrm{Ho}_{2} \mathrm{O}_{3}-\mathrm{TiO}_{2}$ nanolaminate at different annealing temperatures under nitrogen atmosphere in three-dimensional (a) and conventional (b) mode.

Fig. 8

Magnetization vs. measurement temperature (the $1^{\text {st }}$ and $2^{\text {nd }}$ panels from top) and magnetic moment vs. external magnetic field $(\boldsymbol{M}-\boldsymbol{H})$ curves (the $3^{\text {rd }}$ and 4 th panels) for the $\mathrm{Ho}_{2} \mathrm{O}_{3}-\mathrm{TiO}_{2}$ nanolaminate after annealing at $800{ }^{\circ} \mathrm{C}$ in $\mathrm{N}_{2}$ for $30 \mathrm{~min}$. The temperatures for the $\boldsymbol{M}-\boldsymbol{H}$ curves are indicated by labels. 

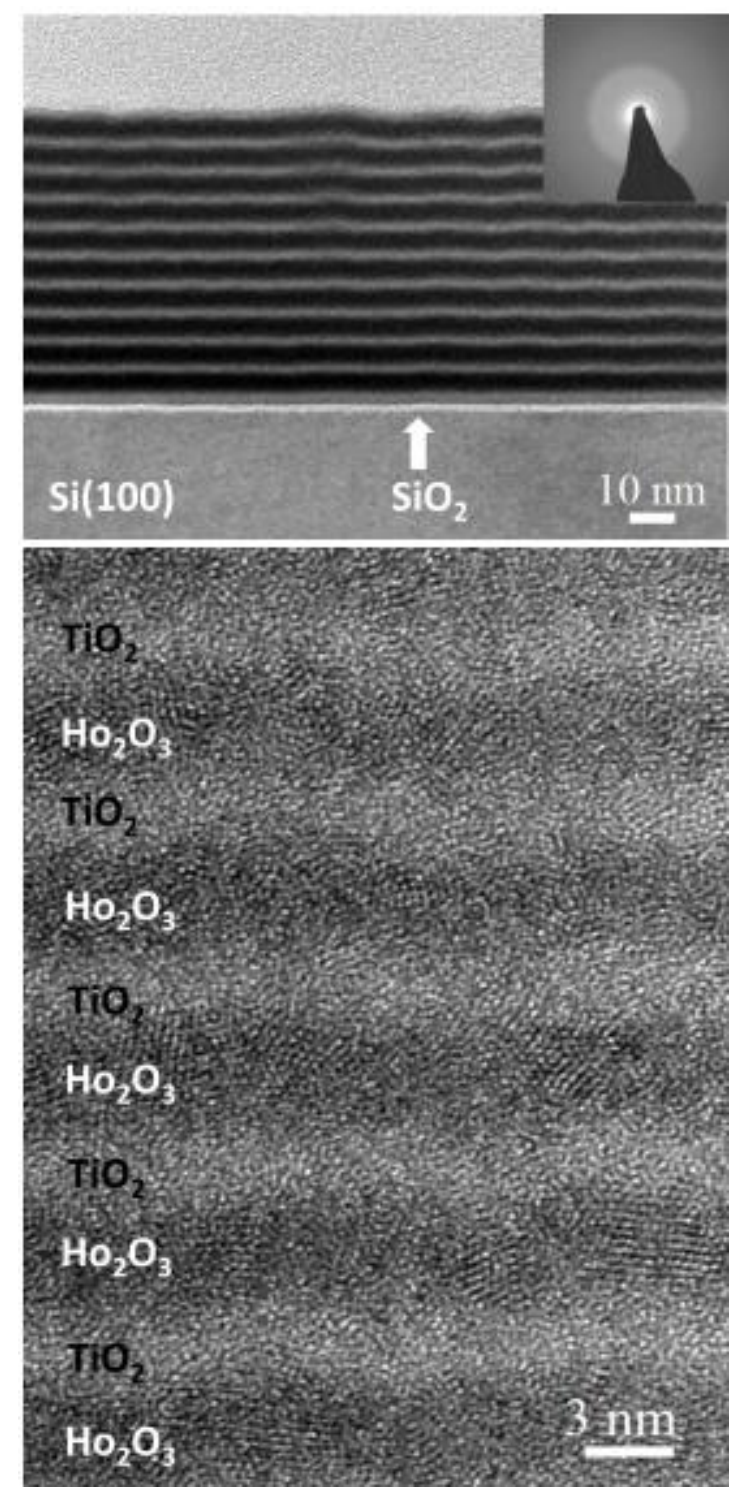

Fig.1 Kukli et al. 

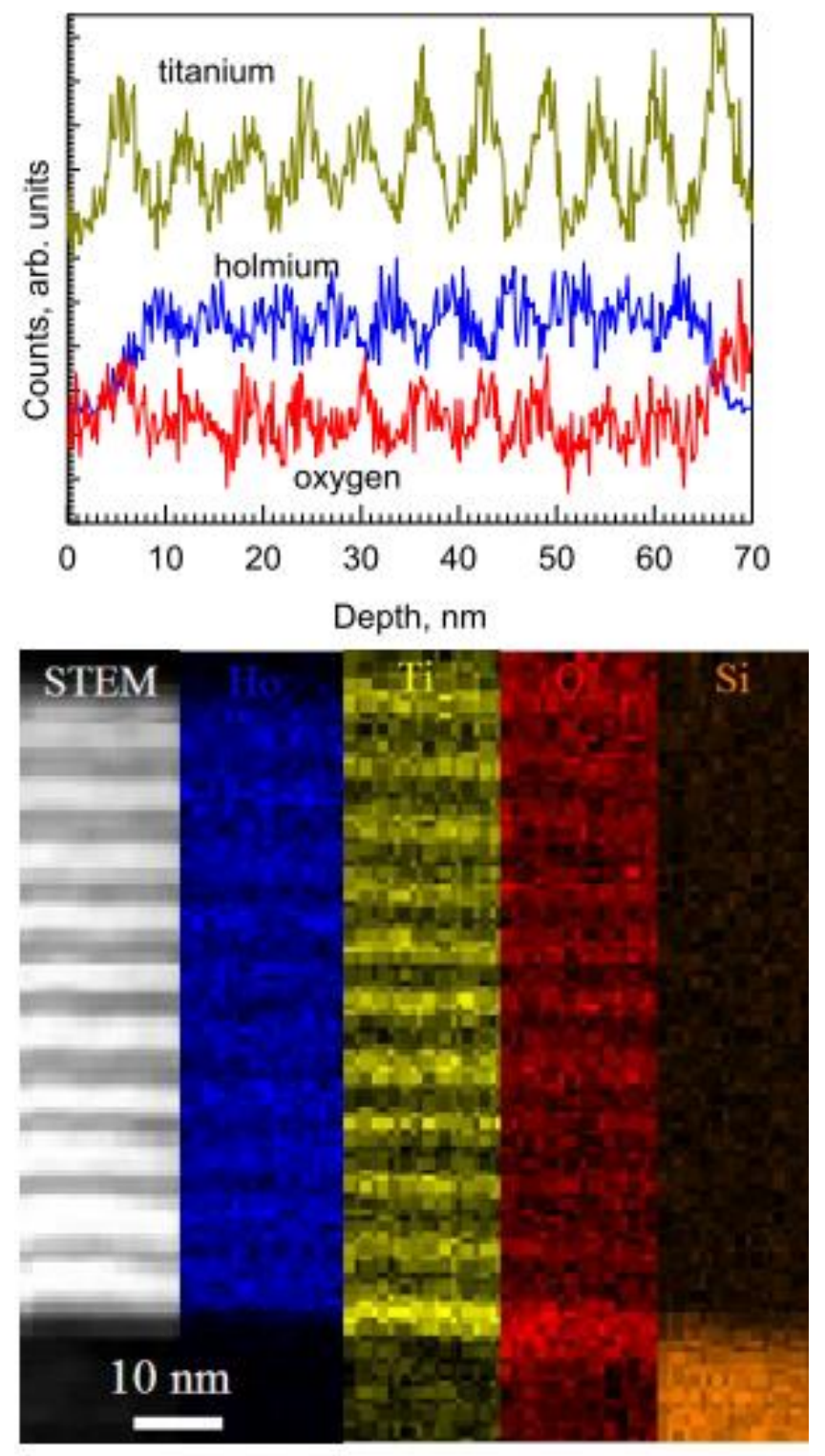

Fig. 2 Kukli et al. 

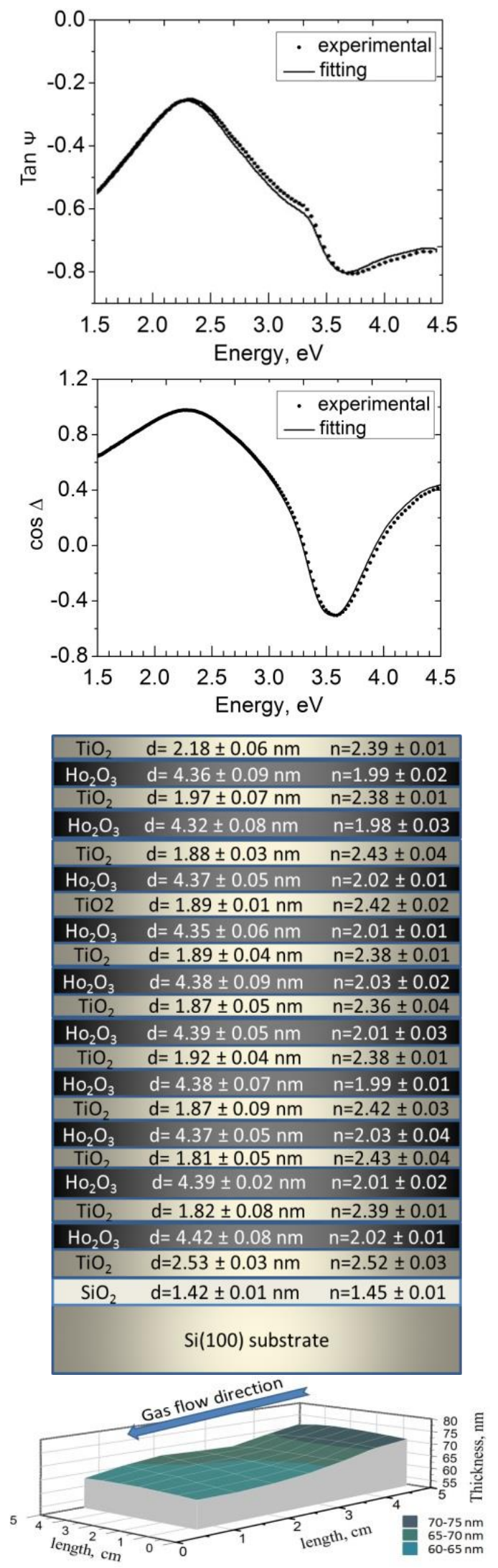

Fig. 3 Kukli et al. 


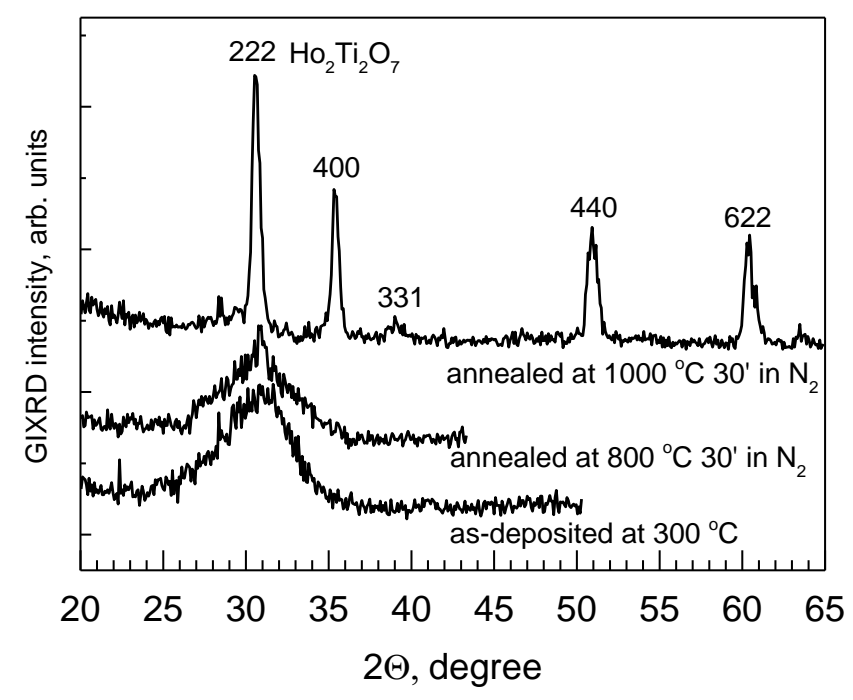

Fig. 4 Kukli et al. 


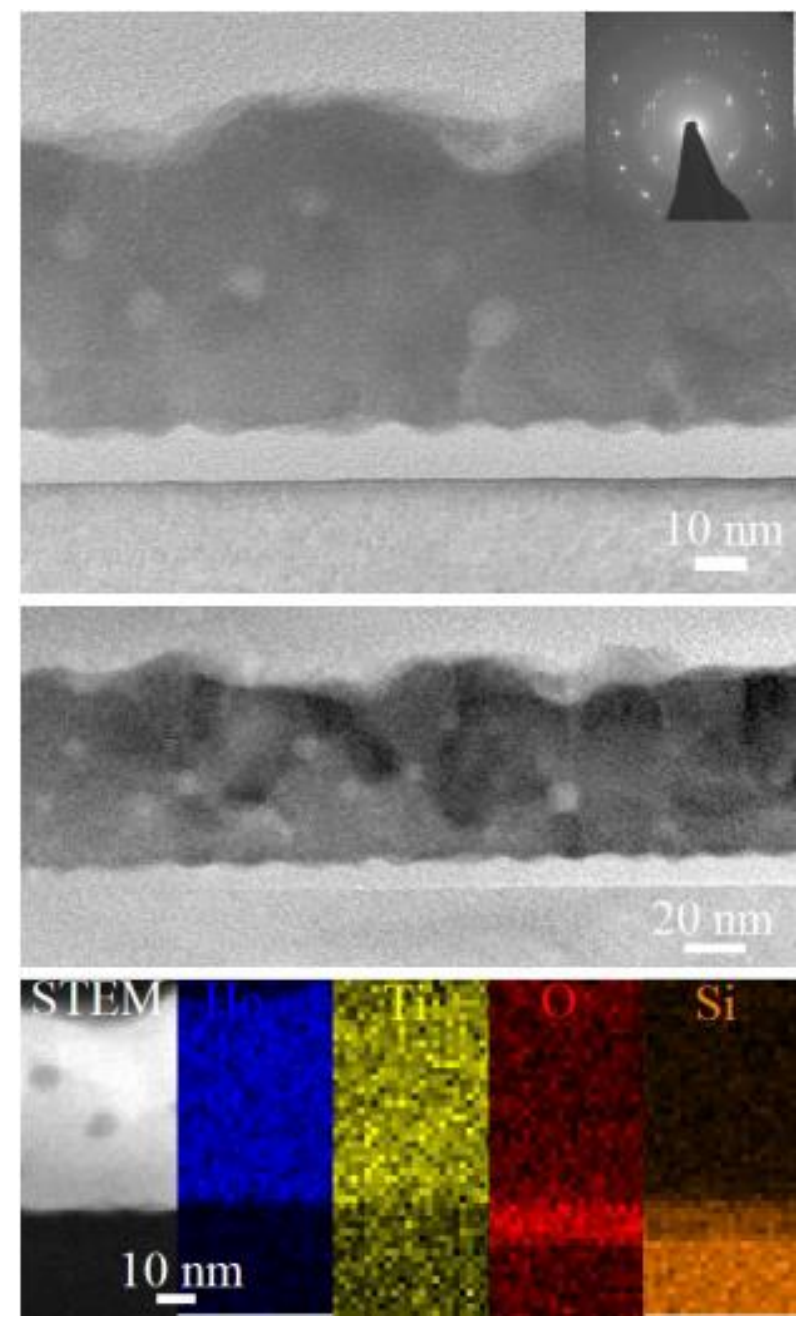

Fig. 5 Kukli et al. 


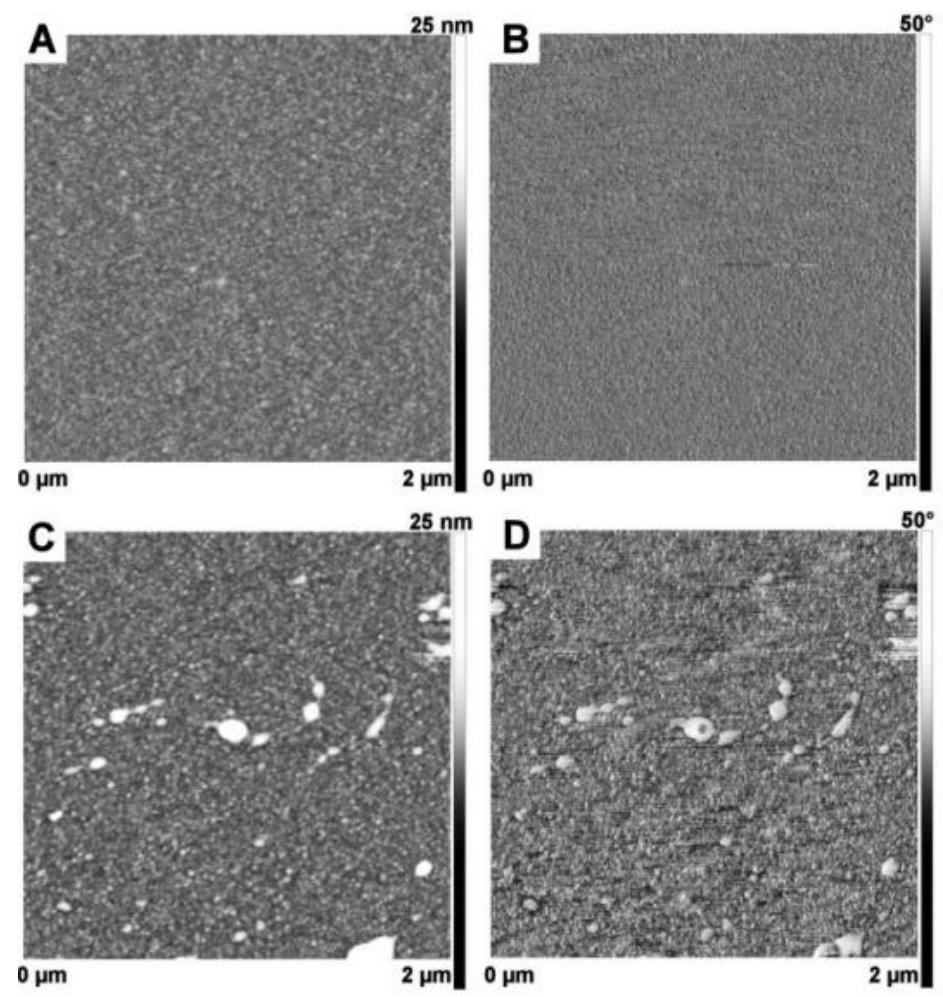

Fig. 6 Kukli et al. 


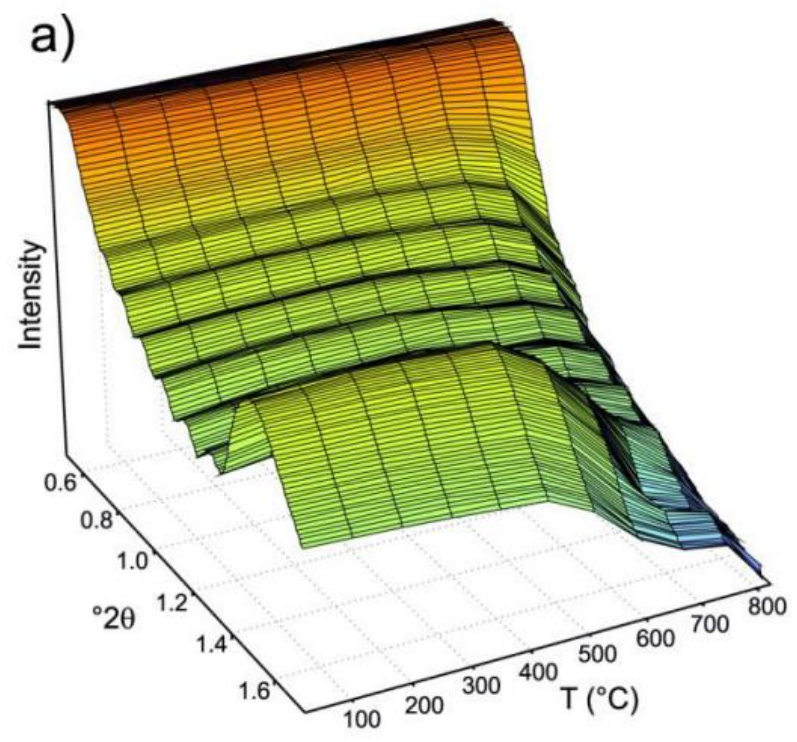

b)

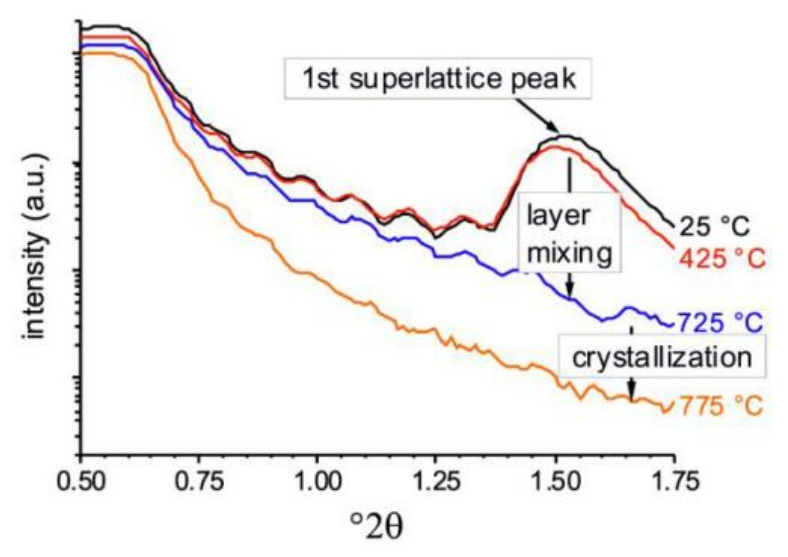

Fig. 7 Kukli et al. 

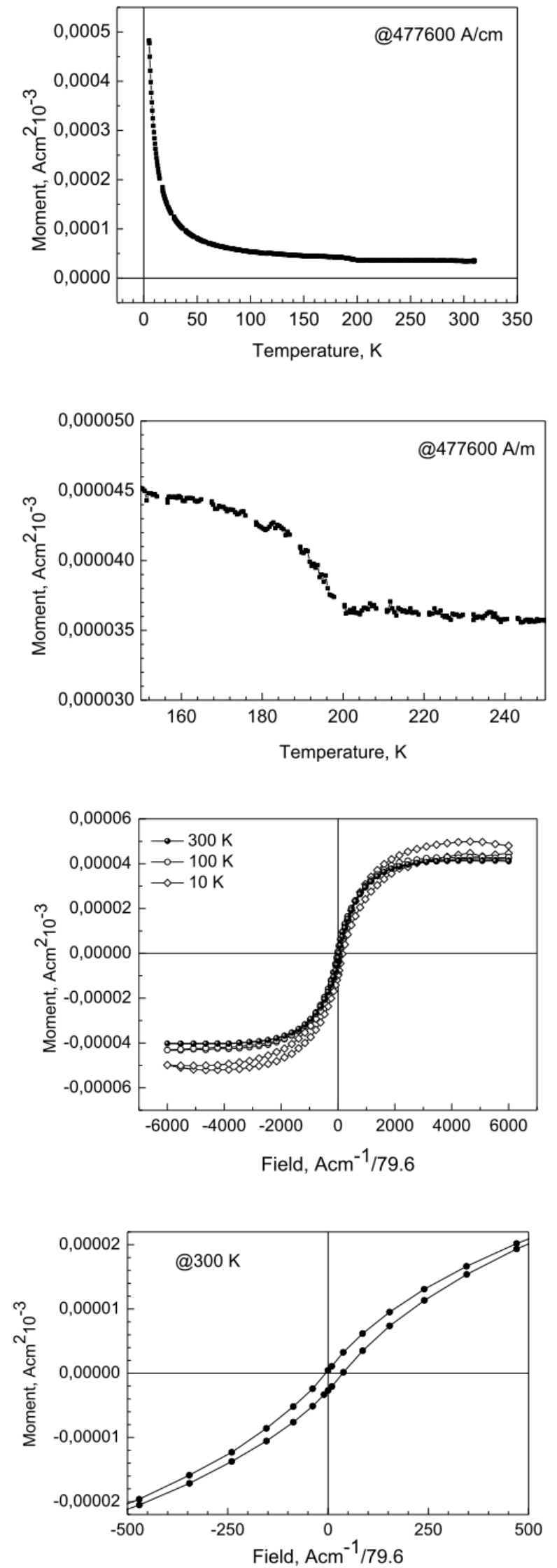

Fig. 8 Kukli et al. 